\title{
El objeto de estudio de la comunicación. Un recorrido teórico y epistemológico
}

\author{
The Object of Study of Communication. A theoretical and Epistemological Tour \\ Uriel Medécigo-Daniel ${ }^{a}$,Alejandra Araiza-Díaz ${ }^{b}$
}

\begin{abstract}
:
Being a young discipline, the debates on the communication's object of study are not yet closed. This article presents a theoretical review through the delimitation of the communication's object of study, and it also tracks the epistemological perspectives that surround these theoretical approaches. Finally, our conclusion is that communication is much more than the study of the media and that it is still necessary to keep on discussing its object of study.
\end{abstract}

\section{Keywords:}

Communication. Theories. Epistemology. Object of Study

\section{Resumen:}

Al ser una disciplina joven, los debates sobre el objeto de estudio de la comunicación no están cerrados. El objetivo de este artículo es hacer un recorrido teórico por la delimitación del objeto de estudio de la comunicación, así como un rastreo de las perspectivas epistemológicas que envuelven estos campos teóricos. Finalmente, concluimos que la comunicación es mucho más que el estudio de los medios y que sigue siendo necesario discutir sobre su objeto de estudio.

\section{Palabras Clave:}

Comunicación. Teorías. Epistemología. Objeto de estudio.

Recibido: 15 de junio de 2018

Dictaminado: 9 de agosto de 2018

Segunda versión: 24 de agosto de 2018

Aceptado: 03 de octubre de 2018.

\footnotetext{
a Pasante de la Licenciatura en Ciencias de la Comunicación, UAEH, Pachuca de Soto, Hidalgo: México, correo electrónico: uriel_medecigo_daniel@hotmail.com

b Profesora-Investigadora del Área Académica de Comunicación, Universidad Autónoma del Estado de Hidalgo. Pachuca de Soto, Hidalgo: México, ORCID: https://orcid.org/0000-0003-0603-7974 Email: araizale@yahoo.es
} 


\section{Introducción}

Vasallo de Lópes (1999) afirma que entender un campo de investigación es recoger su historia epistemológica (cómo se ha realizado la investigación en ese campo) y su historia teórica (cuáles son los tipos de modelos que se han propuesto para comprender dicho campo). Para entender cuáles han sido los paradigmas dominantes en el estudio de la comunicación en una determinada época, es necesario comprender el contexto histórico y geográfico en el que se pensaron, así como las políticas institucionales que predominaron.

Pensamos -al igual que Vasallo de Lópes (1999) y Galindo (1998)- que la epistemología no es sólo el estudio de las formas del conocimiento; es una relación entre el sujeto cognoscente y el objeto de estudio. Así, al asumir un determinado paradigma, no solamente elegimos un marco teórico y unas metodologías adecuadas, sino la forma en la que decidimos posicionarnos con respecto al objeto de estudio. Es decir, optamos por una forma de vincularnos.

En cuanto a la historia del estudio de la comunicación, es importante entender que la producción y el análisis de los medios de comunicación han sido muy relevantes para esta disciplina. Sin embargo, la comunicación es algo mucho más amplio que incluye otras manifestaciones sociales.

La intención del presente texto es hacer un breve recorrido por el acervo teórico de esta disciplina, con el fin de comprender la evolución en la delimitación de su objeto de estudio. Asimismo, buscaremos dilucidar el trasfondo epistemológico en dicha evolución. Por ello, iniciaremos con las teorías clásicas de la comunicación. A continuación, nos detendremos en las teorías contemporáneas. Posteriormente, presentaremos un debate sobre la delimitación del objeto de estudio en clave epistemológica y, finalmente, plantearemos unas breves conclusiones.

\section{El origen de la teoría de la información}

\section{/comunicación}

En el estudio de la comunicación abundan las metáforas. Así, se concibió la comunicación como un tejido social metáfora tomada del tejido biológico-. Ésta puede compararse con los sistemas vascular y nervioso. Por un lado, la comunicación -entendida como sistema vasculares la responsable del flujo de todo lo que existe en la vida social; mientras que -como sistema nervioso- la comunicación posibilita la gestión de relaciones complejas de un centro dominante con las periferias (Mattelart \& Mattelart, 1997). Entonces, al igual que con los sistemas biológicos, es posible estudiar a estos sistemas de comunicación a partir de su composición (estructural) y a través de las funciones que desempeñan.
De este modo, se ha observado que estas dos corrientes teóricas (estructuralismo y funcionalismo) han analizado la comunicación de forma distintita. Por un lado, el funcionalismo se ha encargado inicialmente de describir el proceso de la comunicación y sus elementos; $y$, por el otro, la corriente estructuralista ha buscado explicar el fenómeno del lenguaje inmerso en la comunicación y también las relaciones de poder que intervienen en ello. Esto último, puesto que se ha vinculado en cierto grado con la corriente marxista.

Ahora bien, la tarea que nos hemos propuesto en este apartado es recoger algunos de los aportes más significativos del funcionalismo, en tanto que se les ha conocido como las teorías clásicas de la comunicación. El estructuralismo, por su parte, hemos considerado más pertinente tratarlo en el apartado de las teorías contemporáneas.

El comienzo de los estudios de la comunicación se remonta a la primera mitad del siglo $X X$, que en sus primeras acepciones fue considerada como un acto unidireccional sumamente poderoso, capaz de influir de manera directa sobre el pensamiento y acciones de las personas. De acuerdo con Wilbur Schramm (1982), son cuatro los padres fundadores del estudio de la comunicación: Harold Lasswell, Paul Lazarsfeld, Kurt Lewin y Carl Hovland. La comunicación se ha considerado una disciplina apoyada en dos ciencias principales: la psicología y la sociología.

Estos cuatro investigadores -de origen estadounidensese encargaron de describir la comunicación a partir de la observación de la conducta, las actitudes de grupo, la percepción, las audiencias y la propaganda. Ello corresponde al inicio del funcionalismo desde la comunicación. Estas primeras investigaciones multidisciplinarias dieron paso a los primeros modelos de comunicación, en los cuales es posible identificar los elementos necesarios para un proceso de comunicación. Se ha determinado que el funcionalismo pretende explicar las prácticas e instituciones sociales en función de las necesidades sociales y de los individuos (Merton en McQuail, 2000). Con base en este supuesto, podemos decir que bajo la perspectiva funcionalista se entiende que los medios satisfacen necesidades sociales como lo son el orden, la integración, la socialización, la adaptación, entre otras.

De acuerdo con Denis McQuail (2000), el funcionalismo ha sido seriamente criticado por no tomar partido en las cuestiones referidas al poder y a los conflictos, es decir que se ha considerado a dichos aportes más "integrados" que "apocalípticos" -en palabras de Eco- al tratar el tema de la comunicación de masas, esto es que no cuestionan los procesos de control social y el papel de los medios de comunicación al servicio del poder. 
Las teorías de la comunicación generadas por la corriente funcionalista han sido citadas y criticadas, reconocidas y desfasadas. Sin embargo y dada la relevancia que estas corrientes han tenido para el estudio de la comunicación, pensamos que no pueden ser fácilmente descartables si es que queremos seguir trabajando en la delimitación de su objeto de estudio. Por ello, en este apartado nos proponemos recoger algunas de las teorías más representativas del funcionalismo.

Una de las primeras consideraciones en el ámbito de la comunicación masiva hace referencia -sin duda- a las funciones clásicas de la comunicación propuestas por Lasswell, las cuales son la respuesta a la necesidad de los individuos en un entorno frente a los medios. Estas son: supervisión del entorno, correlación y transmisión de la herencia social. Tiempo después, Charles R. Wright agregó la cuarta función (en Lozano, 2007), la del entretenimiento -aunque algunos investigadores se la atribuyen a Robert K. Merton y a Paul Lazarsfeld- (en Mattelart \& Mattelart, 1997). Esta función es la que más llamaría la atención de futuras investigaciones para abrir paso a la teoría de usos y gratificaciones.

La primera reconsideración de los efectos de los medios se localiza dentro del mismo funcionalismo, puesto que Lazarsfeld, Katz y Menzel (en Schramm, 1982) analizaron los procesos de opinión pública a través de la observación del comportamiento de los votantes en Estados Unidos, de donde se desprende el modelo de flujo de comunicación de dos pasos, el cual está basado en la idea de que: "l'ésser humá no és un essér que viu aïllat socialment, sinó que és un participant actiu de moltes relacions interpersonals" (en Rodrigo \& Estrada, 2008: 38). Con estas premisas se abandona la idea de la comunicación como herramienta de manipulación y les atribuye a los sujetos la capacidad de audiencia.

En los años 60, Joseph Klapper observó que las personas se exponen a los medios de forma selectiva, es decir, que buscan obtener un resultado predeterminado de dicha exposición. Este enfoque va en contra de la primera perspectiva conductista, la aguja hipodérmica. Esto es que, según Klapper (en Lozano, 2007), los medios de comunicación no tienen la capacidad de cambiar actitudes ni conductas, sino que se encargan únicamente de reforzar posiciones previas a la exposición. Asimismo, los medios solo son una opción frente a una fuente de necesidades, es decir que una persona puede escoger entre mirar televisión, practicar algún deporte, leer distintos materiales o asistir a reuniones recreativas para entretenerse. Dicho esto, se entiende que el enfoque considera activa a la audiencia, por su capacidad de tomar decisiones en cuanto a la exposición y elección de contenidos mediáticos.

Ahora bien, otro de los primeros aportes realizados al proceso de la comunicación fue el de Claude Shannon y Warren Weaver (en Castro y Moreno, 2006), quienes buscaron aproximarse a un modelo que permitiera explicar la comunicación a partir de las máquinas. Con una visión desde las matemáticas, el aporte más significativo que expone su modelo al proceso comunicativo es el concepto de "ruido".

La propuesta de Shannon y Weaver fue conocida inicialmente como la teoría de la información, aunque pasó a ser conocida mayormente como teoría matemática de la comunicación. Es indispensable observar que este aporte teórico data del año 1948, esto significa que surge casi a la par que el modelo que ha sido acreditado como el primero en explicar el proceso de la comunicación: el paradigma de Lasswell, que se presentó entre 1945 y 1948.

El paradigma de Lasswell permitió observar los elementos básicos del modelo hasta ese momento, tales como son un comunicador, el mensaje, un canal, un receptor y un efecto (en McQuail, 2000). Dichos elementos dan razón de que en la primera consideración de la comunicación, esta no podría entenderse como un "proceso de intercambio de información" sino como una "trasmisión de mensajes de un emisor a un receptor", cabe recalcar que en esta definición, se consideró a la comunicación como sumamente poderosa, capaz de permear sobre las conductas y pensamientos de las personas. En todo caso, en este "paradigma" se deja ver que lo que se trasmite en la comunicación son mensajes y no -precisamente- información. 
Como lo alude John Durham Peters (2014: 24): "comunicación es una palabra con una amplia historia. Proveniente del latín comunicare, es decir impartir, compartir o hacer común". Pensado de esta manera y desde su concepción básica etimológica, no podemos considerar que la comunicación pueda reducirse a una simple transmisión de información, de mensajes, de datos o de lo que sea, sino que supone la interacción entre los humanos.

Peters (2014) también expone que, en las primeras consideraciones de la comunicación, ésta fue entendida como una transferencia o transmisión. Una transferencia física, como se observaba con el calor, con el magnetismo, o con la luz. Esta idea remite nuevamente a Shannon y Weaver, que también desde las ciencias exactas se aproximaron a definir la comunicación como una trasmisión, aunque su visión ya no suponía elementos desde la física, sino desde las matemáticas, como lo son los datos.

Otro de los grandes pensadores de las matemáticas fue Alan Turing, cuyos estudios también pueden aprovecharse para pensar la comunicación/información. Tal como lo menciona Huget (2014), Claude Shannon y Alan Turing figuran como los pioneros de la informática. Y Shannon -en concreto- sentó las bases para las tecnologías de la información.

Turing desarrolló una máquina capaz de generar algoritmos, que sirvieran para descifrar mensajes que fueron estratégicos durante la segunda guerra mundial. Su trabajo consistía en decodificar los mensajes del bando opuesto para descubrir sus estrategias de guerra. De este modo, explícitamente Turing encodificaba datos por medio de símbolos (código binario) que entraban a la máquina para generar los algoritmos (en González, 2011). Así, pues, se trataba de un input y un output. Se observa que este modelo hablaba de un emisor y un receptor. Sin embargo, en esta concepción de "comunicación" no se trata precisamente de comunicación humana -digamos intersubjetiva-.

Lo que sí es importante recalcar es que la máquina de Turing remite al elemento del mensaje. Para Berlo (en Blake \& Haroldsen, 1975), existen tres factores importantes para que algo se pueda considerar un mensaje: el código, el contenido y el tratamiento. Esto es, para que pueda hablarse de la existencia de un mensaje, debe de existir un código en común entre el destinatario y la fuente, así como un contenido que tenga una intención y una sistematización para llegar de un lado del "proceso" al otro; o, mejor dicho, desde un lado de la transmisión hacia el otro.

Asimismo, Berlo (1960) consideró que, en el proceso de la comunicación, el mensaje está compuesto por una estructura y un código, y que este código ha sido entendido desde la comunicación como el lenguaje -en tanto que sistema de símbolos y signos que los seres humanos utilizan para comunicarse-.

Si tomamos en cuenta las posiciones anteriores de los elementos de un proceso, no podemos concluir que el funcionamiento de la máquina de Turing suponga una forma de comunicación, ya que la comunicación requiere del lenguaje -entendido como idioma, lengua-. Aunque en las investigaciones en comunicación se ha hablado mucho de "tipos de lenguaje", tampoco se debe suponer que estos en realidad puedan clasificarse como tales. Si bien son un conjunto de signos y/o símbolos, no pueden constituirse como un lenguaje, a lo mucho podrá hablarse de un código (que no necesariamente puede ser entendido por [todos] los humanos.

Para esclarecer lo anterior, resultaría menester plantear las diferencias entre lengua y lenguaje, pero esto sería una tarea más propia de la lingüística, aunque también relevante para la comunicación. Sin embargo, por ahora, no nos hemos propuesto buscar desenredar este hilo, debido a que no es una tarea sencilla y que podría ser tema de otro trabajo.

Por ahora, subrayaremos que la información en la teoría matemática tiene otra connotación, diferente a la que usualmente se tiene desde la comunicación. Aquí, no se considera que la información equivalga a los mensajes. Octavio Uña (2000) expone que la información en la teoría matemática no debe confundirse con el término "significado", ni tampoco se refiere al mensaje en sí mismo, sino a "la medida de nuestra libertad de elección al escoger un mensaje del conjunto de mensajes 
disponibles, aunque muchos de ellos carezcan de significado" (Uña, 2000: 59). El autor expone que la información no se limita al mensaje, sino a la totalidad de la situación.

Con esta consideración se abre paso a la idea de que la información, más que ser un mensaje unilateral que tiene por objetivo introducirse en el destinatario, supone una libertad de elección entre otros mensajes, es decir que una persona puede obtener datos desde diferentes fuentes (emisores o comunicadores).

Podemos entonces concebir a la información como la transmisión de datos de una fuente a un destinatario, es decir, considerarlo un acto. Esto significa que es de un carácter unidireccional. Y, por el otro lado, para la teoría clásica la comunicación es vista como un proceso de intercambio de mensajes entre dos sujetos; es decir, supone una interacción, puesto que las teorías y modelos posteriores expusieron el elemento "retroalimentación. Así, la comunicación puede entenderse como el proceso social fundamental que permite la existencia de la vida en sociedad (Schramm, 1982).

Aunque reconocemos la crítica realizada al funcionalismo hecha por McQuail, es importante decir que -como apuntan Miquel Rodrigo y Anna Estrada (2008)- no se deben confundir las teorías funcionalistas de la comunicación con las conductistas, puesto que para el funcionalismo -como ya hemos dicho- los medios de comunicación no son instrumentos con un gran poder de manipulación, sino que cumplen una función social.

Por otro lado, dicen los autores: "[...] per al conductisme, els subjectes eren dèbils, estaven atomitzats i podien ser molt susceptibles de manipulació" (Rodrigo \& Estrada, 2008: 29). Entonces, la idea de los medios como manipuladores y omnipotentes, no es propia del funcionalismo, sino del conductismo, de este modo, podemos decir que quizás existe una mala clasificación de las primeras teorías en torno a la comunicación.

Tendríamos entonces que separar a las teorías de Lasswell del resto de las primeras teorías que giraron en torno a la comunicación de masas. Es decir, hablar -por un lado- de las teorías conductistas de la comunicación, que concebían a los medios como herramientas omnipotentes capaces de moldear los pensamientos y conductas; y, por el otro, de las teorías funcionalistas que si bien entendían la comunicación como transmisión de información, evolucionaron a la idea comunicación como proceso y se aproximaron a tomar en cuenta a la interacción.

\section{Surgimiento y evolución de las teorías contemporáneas de la comunicación}

El estructuralismo al igual que el funcionalismo -como corriente teórica gestada en el siglo XIX- bebe de la tradición positivista. El desarrollo de esta corriente coincide en el tiempo con el funcionalismo. Sin embargo, hemos decidido abordar el estructuralismo en este bloque porque su principal influencia la hallaremos en distintas teorías contemporáneas de la comunicación.

En primer lugar, conviene hablar del estructuralismo en lingüística, pues es básico para hablar del giro lingüístico en ciencias sociales. Según Mahecha (2008), Saussure es uno de los creadores de un paradigma en lingüística. Bajo la influencia del positivismo, a inicios del siglo XX, pretendía hacer explicaciones universales sobre la lengua, concebida como un sistema de signos. Hizo una distinción entre lengua y habla. La lengua es un sistema, un elemento constante y homogéneo, que nos permite clasificar y acaso medir la materialidad del lenguaje. Por su parte, el habla se conforma por las manifestaciones individuales e inabarcables. Son fenómenos heterogéneos y particulares (Musante, 2009). Saussure descartó el estudio del habla y, en busca de la sistematicidad y las conclusiones universales, definió la lengua como objeto de estudio de la lingüística. La lengua -dice Kristeva (1998) en su lectura de Saussurees la parte social del lenguaje, exterior al individuo no es modificable por el hablante y parece seguir leyes dentro de un contrato social. Otros pares de conceptos destacables de la teoría saussuriana son significante/significado y paradigma/sintagma. Encontramos este léxico en distintos teóricos sociales de los años sesenta, como Lévi-Strauss o Roland Barthes. 
Con respecto al primero, el teórico de la antropología estructuralista, Tanius Karam (2007) afirma que hizo una aportación al estudio de la comunicación desde el estructuralismo. Para Lévi-Strauss, el estructuralismo era más que una herramienta o un método, era una epistemología. Como Saussure, partía del supuesto de la existencia de categorías universales. El estructuralismo es un modelo que: "busca, sobre todo, conocer el código (sistema de reglas) para explicar la comunicación" (Karam, 2007: 116). Estudia los intercambios entre actores sociales y pone el énfasis en las reglas de ese intercambio. Ya fuera que se intercambiasen personas, bienes o signos (parentesco, economía y lenguaje), LéviStrauss se interesó por las reglas de esa interacción. Su teoría llegó a la comunicación a través de la vertiente lingüística y se integró a la interpretación marxistapsicoanalítica sobre los medios, los relatos y la ideología (Karam, 2007).

Por su parte, las propuestas de Barthes para estudiar las narraciones y para analizar signos y sentidos son muy relevantes para la tradición semiótica más conocida en comunicación, pues plantea la pregunta: ¿por qué y cómo en una determinada sociedad algo (una imagen, un conjunto de palabras, un gesto, un objeto, un comportamiento, etc.) significa? Barthes es un autor con tintes estructuralistas. Utiliza lenguaje saussuriano y como Levi-Strauss- se interesa por las significaciones culturales (García Murillo, 2009).

Si bien es cierto que la semiótica en la tradición norteamericana se asocia al modelo tríadico del filósofo pragmatista Peirce (icono, índice y símbolo), la versión que más se ha trabajado en comunicación es la que proviene del estructuralismo, especialmente en las versiones de Roland Barthes y Umberto Eco.

Según Silvia Gutiérrez (2007), Barthes elaboró -a partir de la concepción del signo y de sus categorías formalesun análisis de los sistemas de connotación por oposición a los fenómenos denotativos. En su propuesta, la ideología aparece como un conjunto de significados segundos o subyacentes (connotados) que excluye del ámbito de los significados denotados. Ello en comunicación se empleó para estudiar los discursos y las imágenes que -a su vez- constituyen discursos.

Ahora bien, una de las fuentes principales para el desarrollo de la semiología europea es el par significante/significado de Saussure, el cual se relaciona con el par connotativo/denotativo de Umberto Eco (bastante similar al de Barthes). En ambos casos subyace la idea del objeto perceptible y el objeto implícito (Vidales, 2006).

Vidales (2006) también se preocupa por el marco epistemológico de los estudios de la comunicación. Y encuentra -con Umberto Eco- que la semiótica estudia todos los procesos culturales como procesos de comunicación. Desde el análisis que hace de la semiótica de la comunicación, hay un interés importante por la significación. "[...] la comunicación sería entonces el componente que articula cada uno de los elementos que intervienen en un intercambio de información en el cual se produce determinado significado" (Vidales, 2006: 3).

Otra de las corrientes que ha dejado cierta huella en los estudios de la comunicación es el postestructuralismo. Son teóricos que no están incómodos con la noción de estructura, pero no reducen sus explicaciones a ésta. Prestan atención al sujeto, así como al hacer y decir en el acontecer histórico. Según lbáñez (2014), el estructuralismo se enfoca en el código o estructura por encima del devenir, el sujeto y las prácticas. Los sujetos no son constituyentes, sino que están constituidos. En cambio, el postestructuralismo -surgido al calor del Mayo del 68- cuestiona el humanismo, el ahistoricismo, la razón y la exclusión del sujeto.

De esta corriente, destacan para la teoría de la comunicación los trabajos de Foucault y Derrida. En El orden del discurso, Foucault (1970) se interesa por llegar al origen de los discursos en aras de ver lo que se repite, así como lo contingente, lo que cambia. Busca hallar las huellas de lo prohibido, pero también de lo aceptado, lo que excluye un discurso y lo que afirma. Para él, los discursos son vistos como prácticas sociales y producciones culturales. La teoría de la comunicación se enriquece mucho con la visión del discurso -en tanto que 
prácticas sociales- propia de Foucault. Su visión para estudiar el poder también aporta nuevas miradas que van más allá del Estado como centro rector del poder.

Ahora bien, el concepto de deconstrucción de Derrida se complementa muy bien con el propio de Foucault de discurso, en tanto productor de realidad social. La deconstrucción implica -para Derrida- la fragmentación de los textos para detectar los fenómenos marginales o reprimidos por un discurso hegemónico. Este ejercicio busca lo otro, lo diferente. Son lecturas subversivas y no dogmáticas de los textos (Kireger, 2004). El poder es sin duda un asunto crucial para estos autores, que plantean -a diferencia de los funcionalistas- una lectura crítica y la búsqueda de prácticas de libertad. Porque, en efecto, el poder está en todas partes, en la estructura y en los sujetos mismos, pero los sujetos también pueden tener otros agenciamientos. Seguimos viendo cómo la realidad se concibe como textos o discursos y cómo la comunicación puede abordarse desde otra perspectiva, diferente a la mera transmisión de información. Mucha de su influencia la hallaremos en distintas versiones del análisis del discurso, tales como la de Regine Robin, para quien el discurso es "una toma de posición del sujeto frente al conjunto de representaciones, al cuadro ideológico que lo gobierna y del que a la vez es soporte, en tanto producto del discurso" (Gutiérrez, 2007: 117).

Como el postestrucuralismo, que buscan explicar la dominación (pero desde posiciones distintas), tenemos la teoría crítica. Es un tipo de teorías, que -como el estructuralismo- buscan un código común de reproducción social. Su innegable influencia marxista está presente en la concepción de aparatos hegemónicos, cuyo papel en los procesos de socialización es altamente relevante. A decir de Sazbón (2002), el legado de esta corriente teórica, asociada a la Escuela de Frankfurt, debe entenderse como una teoría política. Por eso su influencia en comunicación se asocia a teorías más próximas a la política y a la cultura.

Así, los teóricos de la Escuela de Frankfurt (Adorno, Fromm, Marcuse, Horckheimer, entre otros) desde los años treinta concibieron a los medios de comunicación como uno de estos aparatos hegemónicos. Algunas de las propuestas importantes para el estudio de la comunicación son, por un lado, las industrias culturales, las cuales refuerzan una ideología única a partir de diferencias simuladas. Para Adorno y Horkheimer, los medios son grandes monopolios, controlados por "dirigentes supremos" que perpetúan una única ideología. Por otro lado, hablaron de la racionalidad técnica, pues las industrias culturales se sirven argumentaba Marcuse- de la evolución tecnológica y usan esa clase de razonamiento para ejercer un control más efectivo.

Finalmente, el hijo más joven de esta escuela, Habermas planteó la teoría de la acción comunicativa. Según Sazbón (2002), la teoría de la acción comunicativa de Habermas supone una teoría de la racionalidad y de la modernidad, que sirvió a su autor para realizar una evaluación crítica del pensamiento contemporáneo. Para este teórico, los actos comunicativos cumplen la función de integración y de mantenimiento del sistema social. Aquí también se asoma una concepción de la comunicación como discurso. Sin embargo para Habermas, la racionalidad weberiana juega un papel central (Igartua y Humanes, 2004). Es decir, aunque hay en la teoría crítica un importante distanciamiento frente a la modernidad, aún vemos una defensa de los valores modernos, tales como: la racionalidad o la libertad.

Por otra parte y con cierta influencia de la tradición marxista, los estudios culturales también han dejado huella en el estudio de la comunicación. Son estudios interdisciplinares -gestados en la academia británica- que ponen la cultura en el centro y proponen un análisis basado en la interpretación (Reynoso, 2000). Así y de acuerdo con Mattelart y Neveu (2004), esta corriente surge al calor de la Escuela de Birmingham, en Inglaterra, a mediados de los años sesenta. Según Gómez (2009), los estudios culturales se caracterizan desde sus orígenes- por: la investigación sobre los textos, la investigación sobre los contextos de consumo, su tendencia al diálogo interdisciplinar y la investigación entendida como actividad política. 
Reynoso (2000) se basa en Grossberg para clasificar la evolución de los estudios culturales en cinco etapas: a) humanismo literario, de 1957 a 1969, cuyas figuras claves fueron Richard Hoggart y Raymond Williams; b) sociología dialéctica, de 1969 a inicios de los años setenta, época en la que se fundó el Centro Contemporáneo de Estudios Culturales y en la que destacó el trabajo de Stuart Hall, así como un cierto diálogo con el estructuralismo y la semiología francesa; c) culturalismo, etapa de los años setenta, en la que de nuevo sobresalió el trabajo de Stuart Hall y su lectura de Althusser; d) estructural-coyuntural, de finales de los setenta a principio de los ochenta, etapa en la que Hall incorporó las ideas de Gramsci a través de Laclau; y) posmoderna-coyuntural, de 1985 a inicios de los años noventa con Grossberg a la cabeza. Según Reynoso (2000), la etapa posmodernista mantiene desarrollos en la escuela británica con figuras como Angela McRobbie culturalista postfeminista-, pero también se echa a andar la escuela norteamericana con teóricos como Norman Denzin.

Con Mattelart y Neveu (2004), pensamos que la Escuela de Birmingham ya propició una perspectiva más allá del marxismo con el marxismo. Ello es más notorio en los trabajos de Stuart Hall, impregnados por su procedencia jamaiquina. En efecto, hay reflexiones importantes sobre el hecho colonial en la propuesta culturalista de Hall, así como una relectura del marxismo, que -en su caso- se verá en la apropiación de las ideas de Gramsci. Con ello, el concepto de ideología se complejizó y se pudo entender mejor la tensión entre culturas hegemónicas y culturas subalternas. Esto es de suma importancia en los estudios de la comunicación, cuyo objeto de estudio se traslada a la cultura, especialmente, en lo que América Latina respecta. Hallaremos fuertes influencias de ello en Jesús Martín-Barbero y su teoría de las mediaciones, a través de la cual se ve el estudio de la dominación, pero también el de la resistencia*.

\footnotetext{
* Estamos conscientes de que no hemos hecho un análisis de las teorías latinoamericanas de la comunicación, las cuales merecerían un artículo aparte, en el que se rastreara sus desarrollos propios, así como las influencias que han
}

Así y de acuerdo con Gómez (2009), si bien pueden reconocerse dos enfoques que estudian la cultura en comunicación: la sociología crítica y los estudios culturales, sus aportaciones son particularmente diferentes. El primero -marcado por la Escuela de Frankfurt y cristalizado en la noción de induras culturales- tiene una visión sobrevalorada de los medios masivos de comunicación; mientras que el segundo, el de los estudios culturales, asume que los medios producen cultura y se interesa por los cambios tecnológicos y por la apropiación de los consumidores que ya no son vistos como entes pasivos.

Proveniente de otras latitudes, también es importante destacar al interaccionismo simbólico. Herbert Blumer, George Herbert Mead o Irwing Goffman son autores que -a finales de los años treinta- compartieron el interés de analizar a la sociedad en términos de interacciones sociales (Rizo, 2004). Desde su óptica, la comunicación es un proceso de interpretación de significados que se producen en dichas interacciones. Asimismo, para la Escuela de Palo Alto (afín a estas teorías), todo comportamiento humano tiene un valor comunicativo (Rizo, 2004).

Aunque para Rodrigo y Estrada (2008), el interaccionismo simbólico tiene sus inicios en otras corrientes teóricas tales como el conductismo y el pragmatismo, consideramos que en realidad tiene fuertes influencias de la fenomenología, puesto que aborda tanto al sujeto como a la intersubjetividad: El interaccionismo al igual que Husserl o Merleau Ponty- busca la formulación de la experiencia del mundo. Así, Marta Rizo toma en cuenta la noción de self -como Shütz o Meadpara explicar la naturaleza simbólica de la vida social y asociarla con la capacidad de interpretar del ser humano (Rizo, 2004; 2006).

Esta visión de la comunicación rompe con las concepciones de los años 50, puesto que pone el énfasis en la construcción de sentido a través de la interacción

tenido de teorías clásicas y contemporánea de la comunicación. Un ejemplo de este tipo de tratamiento se puede consultar en Scolari y Rodríguez-Amat (2018), en su artículo sobre el concepto de mediación en la teoría latinoamericana. 
de las personas y del conocimiento social (Rodrigo y Estrada, 2008). Éste es otro de los aportes que permite abandonar la idea de la comunicación como una simple transmisión de información. Así, para que la sociedad funcione, es necesario que exista una reciprocidad entre los miembros que conforman los grupos sociales.

De este modo, el interaccionismo simbólico coincide con la Escuela de Palo Alto, pues ambas corrientes consideran que los seres humanos forman parte de la comunicación, en el sentido de que -en la interacción entre ellos- existe siempre un intercambio de mensajes que ayudan construir el mundo simbólico. Logran, así, una producción de sentido mucho más amplia que la de una simple transmisión de datos. Esta perspectiva no deja a un lado elementos tales como la proxémica, la gesticulación, la metacomunicación y la retórica. Entonces, tanto el interaccionismo simbólico como la Escuela de Palo Alto nos ayudan a reafirmar que la comunicación es un proceso mucho más complejo que no debe ser estudiado únicamente desde la multidisciplinariedad, sino que -dada su naturaleza- la complejidad debe tomarse en cuenta al momento del estudio.

Finalmente, no queremos dejar de mencionar una teoría tan importante para la comunicación de hoy, como lo es la cibercultura. Galindo (2006) afirma que la cibercultura indica la emergencia de un gran salto a partir de la proliferación de nuevas tecnologías, las cuales modifican nuestros escenarios de comunicación e interacción. En ese sentido, Orozco y González señalan que:

[...] el tránsito hacia la llamada sociedad de la información o sociedad de redes se complejiza, dinamiza y expande. Ahí, cada vez más, los procesos mediáticos y comunicativos articulan otros [...] fenómenos sociales, al tiempo que fomentan la aparición de realidades antes inexistentes (Orozco y González, 2011: 17).

Huelga decir que esta teoría tiene grandes alcances para repensar la comunicación misma. De acuerdo con Pierre Lévy (1997), una de las características de esta era posmoderna es el universal sin totalidad. El problema de la modernidad -desde su óptica-no era tanto la pretensión de universalidad, sino que ésta producía efectos totalizantes. En cambio, la nueva era sí busca una suerte de aldea global -como soñó McLuhan-, una universalidad, pero sin efectos totalizadores. La modernidad -dice este autor- unió la escritura a lo universal y a la totalidad y -con ello- marcó la comunicación mediada. El ciberespacio, por su parte, nos devuelve a la situación previa a la escritura (pero a otra escala y en otra órbita), "en la medida en que la interconexión y el dinamismo en tiempo real de la memorias en línea hacen de nuevo compartir el mismo contexto, el mismo inmenso hipertexto vivo, con los interlocutores de la comunicación" (Lévy, 1997: 91). Pero, a diferencia de la escritura -que exigía por la descontextualización un cierre semántico (universal y total)-, "este universal ya no totaliza a través del sentido, sino que reenlaza por el contacto, por la interacción general (Lévy, 1997: 92). En efecto, el estudio de la comunicación cobra otras dimensiones. Pero, ¿qué pasa con la cultura? En palabras de Castells:

La expresión cultural pasa a tomar como modelo el caleidoscopio de un hipertexto global y electrónico. Alrededor de Internet y los multimedia, se hallan hipervinculadas múltiples manifestaciones de la creación y la comunicación humanas [...] Puede que las experiencias individuales existan fuera del hipertexto, pero las experiencias colectivas y los mensajes compartidos, es decir, la cultura como medio social, son en general capturados en este hipertexto, que constituye la fuente de la virtualidad real como marco semántico de nuestras vidas (Castells, 2001: 118-119).

Tras este breve recorrido, que seguramente no ha alcanzado a recoger toda la tradición teórica de esta disciplina, nos gustaría plantear algunas cuestiones que creemos relevantes con respecto a la concepción del objeto de estudio de la comunicación.

Nos parece oportuno señalar que en las teorías contemporáneas de la comunicación sobresalen como elementos para la construcción del objeto de estudio: el lenguaje, el poder, la cultura y la interacción. En el primer 
caso, hay un tránsito de la lengua con Saussure a la semiología con Barthes y Eco; también encontramos un interés por la significación y la producción de sentidos en el interaccionismo simbólico $\mathrm{y}$, finalmente, un desplazamiento hacia el discurso con Foucault y Derrida. El poder es central para los postestructuralistas y para la teoría crítica de la Escuela de Frankfurt. Para los primeros, el poder no es total o vertical; mientras que para los otros sí lo es. La cultura, si bien ya se asoma en las tradiciones post y estructuralista, está ampliamente trabajada en la teoría crítica con las industrias culturales y su concepción vertical del poder, así como en los estudios culturales que dan pie a una visión más próxima a la reapropiación. Encontraremos huellas de esto en la cibercultura. Finalmente, la interacción está presente en el interaccionismo simbólico, en el sentido de que la comunicación se encuentra en la naturaleza del ser humano, en tanto que es capaz de generar un mundo simbólico, al tiempo que tiene una capacidad de interpretación que permite darle sentido a las relaciones que se generan a raíz de las interacciones, es decir, sobre la base de la intersubjetividad. También hay una concepción muy interesante de la interacción, que se replantea en la era de la virtualidad en la cibercultura.

Ahora bien, ¿de qué nos sirve este recorrido? Ahondaremos un poco más en esto a continuación.

\section{El objeto de estudio de la comunicación. Apuntes epistemológicos}

Decíamos con Vasallo de López (1999) que para entender un campo disciplinar hay que recoger su historia teórica y epistemológica. En cuanto al estudio de la comunicación, hemos ido explicando su evolución teórica con respecto a la delimitación del objeto de estudio. Nos gustaría aclarar que también se puede ver un tránsito en las posiciones epistemológicas. Así, si bien las teorías clásicas de la comunicación, tanto el conductismo como el funcionalismo, tienen una fuerte influencia positivista, también hallamos huellas de esta corriente en el estructuralismo. Ahora bien, las teorías contemporáneas de la comunicación van mostrando una clara evolución hacia corrientes epistemológicas críticas frente el positivismo. Se puede decir que hacen un tránsito hacia el posmodernismo. Ya sea desde el giro lingüístico, el giro hermenéutico o interpretativo, el giro cultural, el postestructuralismo o la teoría crítica, vemos una tendencia a prescindir de las verdades absolutas, al tiempo que emerge -como no estaba tan claro en las teorías clásicas- una postura de rechazo frente al poder.

Es a partir del siglo XX, cuando se observa en los paradigmas críticos una concepción clara de la ciencia como práctica social. Ello marca una distancia con respecto a la manera de entender el pensamiento científico de la modernidad (García, 2006). Al concebir la ciencia como práctica social, se le reconoce como actividad humana $\mathrm{y}$, por tanto, como susceptible a generar interpretaciones "erróneas". No es casualidad que muchas de las teorías vanguardistas o posmodernas se centren en criticar la búsqueda de la Verdad absoluta y aboguen por posturas más relativistas, situadas, localizadas y críticas.

Uno de los problemas que vislumbramos con respecto a la delimitación del objeto de estudio de la comunicación tiene que ver con que es una disciplina muy joven, alrededor de la cual aún pesa el debate de si es o no una ciencia. Karam (2007) señala que hay dos tendencias en este debate: quienes consideran que no es una disciplina en sí misma y quienes abogan por que sí se considere una ciencia social específica. Las ciencias sociales fueron las últimas en aparecer y cuando lo hicieron el positivismo estaba en pleno auge. La comunicación como un campo joven fue tocada en la etapa de las teorías clásicas por esa tradición y, en menor medida, en la etapa de las teorías contemporáneas. El campo de la comunicación sigue intentando definir su objeto de estudio, pero lo hace en una época -si se quiereposmoderna en la que el fin de los metarrelatos marca una tendencia a desdisciplinar. Fernández Christlieb (2004) considera que la separación entre teoría, método, objeto e investigación es insostenible. La desdisciplinariedad nos invita a no separar estos elementos y a aceptar el hecho de que cada vez más las ciencias se confunden entre sí. En efecto, "el positivismo legó un ambiente proclive al desarrollo parcelado de las ciencias 
y con poco interés para establecer puentes entre el mundo físico y el mundo mental” (Karam, 2007: 106). Karam cita a Fuentes y Navarro para hablar de la postdisciplinariedad o este movimiento tendiente a borrar y desjerarquizar los límites entre especialidades no desde la superficialidad, sino en busca de relaciones más complejas.

Así, otra de las apuestas epistemológicas propias de la ruptura con el cientificismo y el positivismo, es el pensamiento complejo de Edgar Morin (1990). La complejidad -dice Morin (1990)- se aproxima a lo inquietante, desordenado, inextricable, ambiguo o incierto. Por eso, el paradigma positivista -en aras de asir la inteligibilidad- ha descartado la complejidad, lo cual nos ha vuelto "ciegos" a la hora de conocer, pues sólo miramos aquello "operativizable". Con este autor, Galindo (1998) también nos llama a concebir el estudio de la comunicación desde el paradigma de la complejidad.

Por su parte, Rolando García (1994) dice que la investigación interdisciplinaria es un tipo de estudio que requiere un sistema complejo. Según el autor:

Además de la heterogeneidad la
característica determinante de un sistema
complejo es la interdefinibilidad y mutua
dependencia de las funciones que
cumplen dichos elementos dentro del
sistema total. Esta característica excluye
la posibilidad de obtener un análisis de un
sistema complejo por la simple adición de
estudios sectoriales correspondientes a
cada uno de los elementos (García, 1994:
85).

¿Interdisciplinariedad, desdisciplinariedad 0 postdisciplinariedad? Lo importante es quebrar los límites cerrados, establecer verdaderos puentes y lanzarnos en busca de la complejidad, especialmente con un objeto de estudio, el de la comunicación.

\section{Conclusiones}

Rodrigo y Estrada (2008) consideran que, la comunidad de investigación en comunicación tiene tres posturas diferentes. Primeramente, están los que consideran que la comunicación debe abordarse desde la interdisciplinariedad; a continuación, los que, desde una postura postmoderna, consideran que el establecimiento de una sola disciplina no tiene mucho sentido y que entonces la comunicación no debe tener fronteras disciplinarias. Y, por último, los que defienden que la comunicación debe ser un campo de estudio independiente de las otras ciencias.

Por ahora, hemos alcanzado a dilucidar que la ciencia de la comunicación o comunicología -según Galindo (2005)no pretende abandonar la interdisciplinariedad, sino que busca complejizar el estudio y reconocer que la comunicación ha generado teoría propia. Si bien la comunicología es la más joven de las ciencias sociales, en la delimitación del objeto de estudio de la comunicación sí se han generado distintos debates teóricos -como los que hemos presentado en este texto-. Es así que -con Galindo y otros autores- pensamos que sí es importante defender la posición de que la comunicación es una ciencia. Sin embargo, no podemos asumirla desde una mirada positivista y reduccionista. La comunicación no debe reducirse a la simple transmisión de información. Hablando de este tipo de definiciones, Durham Peters dice:

[...] el concepto comunicación nos complica la tarea de construir mundos conjuntos; nos invita a un mundo de comunidades sin política, de entendimiento sin lenguaje y de almas sin cuerpo, sólo para provocar que la política, el lenguaje y los cuerpos vuelvan a aparecer como obstáculos en vez de bendiciones (Peters, 2014: 53).

Hemos llevado todo este recorrido teórico y epistemológico de la comunicación por un camino que nos lleva a la idea de comunidad, una comunidad en la que la comunicación es parte del bien común, esto es, regresar a la raíz etimológica de la que esta implica: comunicare: impartir, compartir o hacer común. 


\section{Referencias}

Berlo, David (1960) El proceso de la comunicación. México: El ateneo.

Blake, Reed \& Haroldsen, Edwin (1975) Taxonomía de conceptos de la comunicación. México: Nuevomar.

Castells, Manuel (2001) “Epílogo: Informacionalismo y sociedad red”. En: Himanen Pekka, La ética del hacker y el espíritu de la era de la información, pp. 110-124. Disponible en: http://eprints.rclis.org/12851/1/pekka.pdf [Consultado el 12/09/2018].

Castro, Ixchel y Moreno, Luz Zareth (2006) El modelo comunicativo: teóricos y teorías relevantes. México: Trillas.

Fernández Christlieb, Pablo (2004) La sociedad mental. Barcelona: Anthropos.

Foucault, Michel (1970) El orden del discurso. Barcelona: Tusquets, 1999.

Galindo, Jesús (1998) "Introducción. La lucha de la luz y la sombra". En: Galindo, J. (Coord.), Técnicas de investigación en sociedad, cultura y comunicación, pp. 9-32. México: Prentice Hall/Pearson/Addison Wesley.

Galindo, Jesús (2005) "Sobre comunicología y comunicometodología Primera guía de apuntes sobre horizontes de lo posible", Culturales $\mathrm{I}(1)$, pp. 7-28.

Galindo, Jesús (2006) Cibercultura. Un mundo emergente y una nueva mirada. México: Intersecciones.

García, Rolando (1994) "Interdisciplinariedad y sistemas complejos". En Leff, Enrique (Comp.), Ciencias sociales y formación ambiental, pp. 85-124. Barcelona: Gedisa/UNAM/PNUMA.

García Murillo, Ricardo (2009) "Entre el estructuralismo y su post modelos de significación en Roland Barthes", Bajo palabra, Revista de Filosofía, 4, pp. 297-306.

Gómez, Héctor (2009) "Los estudios culturales y los estudios de la comunicación. Las membranas del tiempo y el espacio en la era de la comunicación digital", Razón y palabra, 67, pp. 1-21. Disponible en http://www.razonypalabra.org.mx/N/n67/actual/5hgomez.pdf [Consultado el 12/09/2018].

Gutiérrez, Silvia (2007) "Análisis del discurso político. Un panorama de campo”. En: Gasca, Martín y Gómez, María Eugenia (Comps.), Análisis del discurso. Perspectivas diversas, pp. 89-131. México: UNAM/CELE.

Ibáñez, Tomás (2014) “Adenda 2. El postestructuralismo como punto de inflexión en los modos de pensar”. En Anarquía es movimiento, pp. 113-126. Barcelona: Virus.

Huget, Llorenç (2013, 14 de marzo) "Alan M. Turing y Claude E. Shannon: matemáticas para la informática”, El País. Disponible en: http://blogs.elpais.com/turing/2013/03/alan-m-turing-y-claude-eshannon-matematicas-para-la-informatica.html [Consultado el $12 / 09 / 2018]$.

Igartua, Juan José y Humanes, María Luisa (2004) Teoría e investigación en comunicación social. Madrid: Síntesis.

Karam, Tanius (2007) "Epistemología y comunicación. Notas para un debate", Andamios, 4, pp. 97-124. Disponible en: http://www.redalyc.org/articulo.oa?id=62840705 [Consultado el 12/09/2018].
Krieger, Peter (2004) "La deconstrucción de Jacques Derrida (19302004)", Annales del Instituto de Investigaciones Estéticas, 84: 179188 .

Kristeva, Julia (1988) “Qué es el lenguaje?” En: El lenguaje, ese desconocido, pp. 4-40. Madrid: Fundamentos.

Lévy, Pierre (1997) "Lo universal sin totalidad, esencia de la cibercultura". En: Cibercultura. La cultura de la sociedad digital, pp. 83-94. Barcelona-México: Anthropos-UAM, 2007.

Lozano, José Carlos (2007) Teoría e investigación de la comunicación de masas. México: Pearson Educación.

Mahecha, Miguel Ángel (2008) "La lingüística hoy: su (re)configuración a través de los diferentes objetos de estudio". Forma y función, $21 \mathrm{pp}$. 107-133.

Mattelart, Armand y Mattelart, Michelle (1997) Historia de las teorías de la comunicación. Barcelona: Paidós.

Mattelart, Armand y Neveu, Érick (2003) Introducción a los estudios culturales. Barcelona: Paidós.

McQuail, Denis (2000) Introducción a la teoría de la comunicación de masas. Barcelona: Paidós.

Morin, Edgar (1990) Introducción al pensamiento complejo. Barcelona: Gedisa.

Musante, María Clara (2009) "Saussure y Benveniste. Bases epistemológicas de una transición: de la lengua al discurso". Disponible en: http://sedici.unlp.edu.ar/bitstream/handle/10915/33052/Documento_co mpleto.pdf?sequence $=1$ [Consultado el 12/09/2018]

Orozco, Guillermo y González, Rodrigo (2011) Una coartada metodológica. Abordajes cualitativos en la investigación en comunicación, medios y audiencias. México: Tintable.

Peters, John (2014) Hablar al aire. Una historia de la idea de comunicación. México: Fondo de cultura económica.

Reynoso, Carlos (2000). Apogeo y decadencia de los Estudios Culturales Una visión antropológica. Barcelona: Gedisa.

Rizo, Marta (2004) "El interaccionismo simbólico y la Escuela de Palo Alto. Hacia un nuevo concepto de comunicación", Portal de la Comunicación. Disponible en: http://portalcomunicacao.com/uploads/pdf/17_esp.pdf [Consultado el 12/09/2018]

(2006) "La interacción y la comunicación desde los enfoques de la psicología social y la fenomenología. Breve exploración teórica", Anàlisi, 33, pp. 45-62. Disponible en: https://ddd.uab.cat/pub/analisi/02112175n33/02112175n33p45.pdf [Consultado el 12/09/2018].

Rodrigo, Miquel y Estrada, Anna (2008) Les teories de la comunicació. Barcelona: Vullsaber.

Uña, Octavio (2000) "Teorías y modelos de la comunicación”, Praxis sociológica, 5, pp. 33-79.

Saussure, Ferdinand (1945) Curso de lingüística general. Buenos Aires: Lozada S.A. Moreno.

Sazbón, José (2002) "El legado teórico de la Escuela de Frankfurt". En: Boron Atilio y de Vita, Álvaro (Comps.), Teoría y filosofía política. La 
recuperación de los clásicos en el debate latinoamericano, pp. 181-214. Buenos Aires: CLACSO.

Schramm, Wilbur (1982) La ciencia de la comunicación humana. México: Editorial Grijalbo.

Scolari, Carlos y Rodríguez-Amat, Joan (2018) "A Latin American Approach to Mediatization: Specifies and Contributions to a Global Discussion About How the Media Shape Contemporary Societies", Communication Theory, 28, pp. 131-154. [Consultado el 12/09/2018].

Vassallo de Lópes, María Immacolatta (1999) "La investigación de la comunicación: cuestiones epistemológicas, teóricas y metodológicas", Diálogos de la Comunicación. Revista Académica de la Federación Latinoamericana de Facultades de Comunicación Social, 56, pp. 1-12. Disponible en: https://www.researchgate.net/publication/270217733_La_investigacio n_de_la_comunicacion_cuestiones_epistemologicas_teoricas_y_metod ologicas [Consultado el 12/09/2018].

Vidales, Carlos (2006) "La semiótica como matriz de estudio de la comunicación", UNIrevista, 1(3), pp. 1-12. Disponible en: http://www.scielo.org.mx/scielo.php?script=sci_arttext\&pid=S0188-

252X2009000100003 [Consultado el 12/09/2018]. 